\title{
Multi-variable Optimization of HVAC System Using a
} Genetic Algorithm

\author{
Rongling $\mathrm{Li}^{1}$ and Ryozo Ooka ${ }^{2}$ \\ 1. Graduate School of Engineering, The University of Tokyo, Tokyo 153-8505, Japan \\ 2. Institute of Industrial Science, The University of Tokyo, Tokyo 153-8505, Japan
}

Received: July 14, 2013 / Accepted: September 09, 2013 / Published: February 28, 2014.

\begin{abstract}
Geothermal is a fast-growing alternative heat source for HVAC systems, however, the initial cost of using a ground source HVAC system is higher compared to an air source system. Studies about system design and operation are necessary to reduce the initial cost and ensure that the ground source heat pump system has high efficiency, resulting in a lower total life-time cost. In this study, a multi-variable evolutionary computation algorithm is proposed for generating optimal parameters for a geothermal source HVAC system. The system was modeled and simulated using MATLAB. The design parameters were calculated by minimizing the energy consumption. Based on an experimental building, a case study was presented. Using this model, the optimal set points were calculated and used as a designed system. Energy consumption of this system was reduced by about $10 \%$ compared to the system operated with a fixed supply cold water temperature $\left(7^{\circ} \mathrm{C}\right)$.
\end{abstract}

Key words: Ground source air-conditioning system, genetic algorithm, optimization, MATLAB.

\section{Introduction}

Geothermal is a widely available and increasingly utilized source of sustainable and renewable energy. Development of geothermal energy not only means the elimination of pollutants such as particulates and greenhouse gases but also reduction in heat island effect [1-3]. Unfortunately, due to the expense and effort to bury heat exchangers in the ground or providing wells for the energy sources, the initial capital cost of using ground source heat pumps is about 30\%-50\% higher than air source heat pumps [4]. Therefore, thorough research and calculations are required when designing systems with geothermal heat sources to reduce the initial cost and ensure that the ground source heat pump system has high efficiency, resulting in a lower total life-time cost. The performance of the system depends largely on the ground source heat pump's properties such as

Corresponding author: Rongling Li, Ph.D. candidate, research field: energy efficient buildings. E-mail: lirl@iis.u-tokyo.ac.jp. temperature of supplied cold water, cooling water temperature, heat pump capacity, PLR, etc.. Furthermore, in use, the performance of HVAC systems connect strongly with operating set points and schedule. For an installed HVAC system, the cold water supply temperature is a set point that can be controlled easily.

In this study, we use a genetic algorithm method to find the optimal design of a geothermal heat pump air-conditioning system. Genetic algorithms have been used in building applications related to energy consumption, mostly to optimize the sizing and control of HVAC systems [5-8]. It has also previously been used in ground source heat pump design and component selection [9].

We built a model based on the HVAC system in our experimental building, which was designed for zero-energy consumption and built at the University of Tokyo [10]. In this building, a ground source cooling/heating system is utilized. Currently, we are working on finding the best operating schedule to 
minimize the energy consumption of the system [11]. Here, the authors present the model for optimal set points calculation.

\section{Research Methods}

\subsection{System Configuration}

Based on the experimental building, we built our simulation model in MATLAB. Models of BHE (borehole heat exchangers), a FCU (fan coil unit) and a GSHP (ground source heat pump) chiller were implemented in the simulation model (Fig. 1).
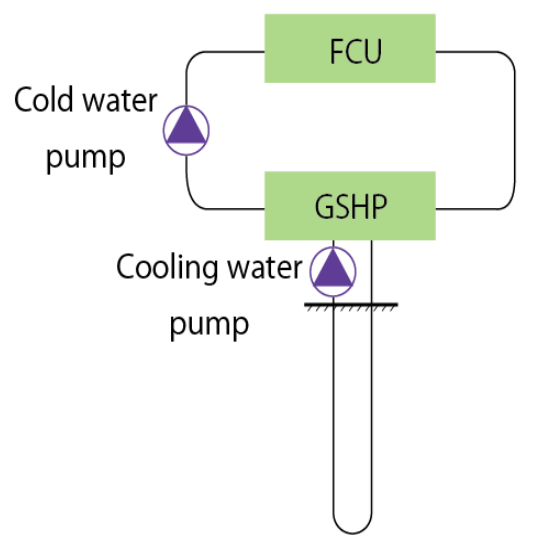

Fig. 1 System configuration.

\subsection{Problem Formulation}

This model was built based on mathematical models of the components in TRNSYS [12], and various equipment catalog data. For any cooling load, the objective of the problem is to minimize total power consumption of the GSHP air-conditioning system $E_{\text {total }}$ while ensuring that the temperature of the air supplied by the FCU $T_{\text {air,out }}$ and the temperature of cooling water returning to the ground heat exchangers $T_{c w, i n}$ stays within their constraint range. That is:

$$
\underset{T_{c h w, s e t}, m_{\text {air }}, m_{c w}}{\text { Minimize }} \quad E_{\text {total }}\left(E_{\text {chiller, }} E_{\text {pump }}, E_{\text {fan }}\right)
$$

Subject to:

$$
\begin{aligned}
& T_{\text {air,out }} \in\left[T_{\text {air,min }}, T_{\text {air, } \max }\right], \\
& T_{c w, \text { in }} \in\left[T_{c w, \text { min }}, T_{c w, \text { max }}\right]
\end{aligned}
$$

Here, the objective function $E_{\text {total }}$ is expressed by Eq. (1).

$$
E_{\text {total }}=E_{\text {chiller }}+E_{\text {pump }}+E_{\text {fan }}
$$

where, the expressions for energy consumption of GSHP chiller $E_{\text {chiller }}$, pumps $E_{\text {pump }}$ and fan $E_{\text {fan }}$ follow Eqs. (2)-(4), respectively.

$$
\begin{aligned}
& E_{\text {chiller }}=Q_{\text {load }} /\left(C O P_{\text {ratio }} * C O P_{\text {nom }}\right) \\
& Q_{\text {load }}=m_{\text {chw }} C_{p w}\left(T_{\text {chw } \text { in }}-T_{\text {chw set }}\right)
\end{aligned}
$$

Table 1 Model nomenclature.

\begin{tabular}{|l|l|l|l|}
\hline$Q_{\text {load }}$ & Current load on the chiller & $m_{c w}$ & Cooling water flow rate \\
\hline$E_{\text {total }}$ & $\begin{array}{l}\text { Total power consumption of the GSHP } \\
\text { air-conditioning system }\end{array}$ & $T_{c w, i n}$ & $\begin{array}{l}\text { Temperature of cooling water returning to the } \\
\text { ground heat exchangers }\end{array}$ \\
\hline$E_{\text {pump }}$ & Energy consumption of pumps & $E_{f a n}$ & Energy consumption of fan \\
\hline$T_{c w, o u t}$ & $\begin{array}{l}\text { Cooling water temperature supplied by underground } \\
\text { heat exchangers }\end{array}$ & $T_{c h w, s e t}$ & Temperature of supplied cold water of chiller \\
\hline$E_{\text {chiller }}$ & Energy consumption of GSHP chiller & $H_{\text {air }}$ & Air pressure of cooling coil fan \\
\hline$T_{\text {air } \text { out }}$ & Temperature of the air supplied by the FCU & $H_{c h w}$ & Pump head provided by cold water pump \\
\hline COP ratio & $\begin{array}{l}\text { Ratio between chiller COP at current conditions and } \\
\text { the nominal COP }\end{array}$ & $\begin{array}{l}C O P_{n o m} \\
\text { Chiller nominal COP } \\
\text { performance) at current conditions }\end{array}$ \\
\hline$m_{\text {air }}$ & Air flow rate of cooling coil fan & Cooling water pump head \\
\hline$P L R$ & Chiller part load ratio & $H_{c w}$ & Total efficiency of cooling coil fan \\
\hline$T_{\text {chw,in }}$ & Temperature of cold water return & $\eta_{3}$ & Specific heat of cold water \\
\hline$\eta_{2}$ & Total efficiency of cooling water pump & $C_{p w}$ & Standard gravity \\
\hline$m_{\text {chw }}$ & Cold water flow rate & $\rho_{s}$ & Air density \\
\hline Capacity & Chiller rated capacity & $\eta_{1}$ & Total efficiency of cold water pump \\
\hline $\begin{array}{l}a_{0} \sim a_{6} \\
b_{0} \sim b_{2} \\
c_{0} \sim c_{3}\end{array}$ & Constant coefficients & $\begin{array}{l}d_{0} \sim d_{6} \\
e_{0} \sim e_{2} \\
f_{0} \sim f_{2} \\
i_{0} \sim i_{2}\end{array}$ & Constant coefficients \\
\hline
\end{tabular}




$$
\begin{gathered}
C O P_{\text {ratio }}=a_{0}+a_{1}(P L R)+a_{2}(P L R)^{2}+\cdots+a_{6}(P L R)^{6} \quad \text { (2c) } \\
C O P_{\text {nom }}=b_{0}+b_{1}\left(T_{c h w, \text { set }} /\left(T_{c w, \text { out }}-T_{c h w, \text { set }}\right)\right) \\
+b_{2}\left(T_{c h w, \text { set }} /\left(T_{c w, \text { out }}-T_{c h w, \text { set }}\right)\right)^{2} \\
P L R=Q_{\text {load }} / Q_{\text {capacity }} \\
Q_{\text {capacity }}=\left(c_{0}+c_{1} T_{c h w, \text { set }}+c_{2} T_{c h w, s e t}^{2}+c_{3} T_{c h w, s e t}^{3}\right) \text { Capacity }_{\text {rated }} \text { (2f) }
\end{gathered}
$$

Eqs. (2c) and (2d) are formulated based on catalogue values shown in Fig. 2.

$$
\begin{aligned}
E_{\text {pump }}= & m_{c h w} g_{s} H_{c h w} / \eta_{1}+m_{c w} g_{s} H_{c w} / \eta_{2} \\
m_{c h w}= & \left(d_{0}+d_{1} Q_{\text {load }}+d_{2} Q_{\text {load }}^{2}\right)\left(d_{3}+d_{4} T_{c h w, \text { set }}\right. \\
+ & \left.d_{5} T_{c h w, s e t}^{2}+d_{6} T_{c h w, s e t}^{3}\right) \\
& H_{c h w}=e_{0}+e_{1} m_{c h w}+e_{2} m_{c h w}^{2} \\
& H_{c w}=f_{0}+f_{1} m_{c w}+f_{2} m_{c w}^{2}
\end{aligned}
$$

Eq. (3b) is based on a set of experimental data shown in Fig. 3 [13].

$$
\begin{gathered}
E_{\text {fan }}=m_{\text {air }} H_{\text {air }} / \rho_{\text {air }} / \eta_{3} \\
H_{\text {air }}=i_{0}+i_{1} m_{\text {air }}+i_{2} m_{\text {air }}^{2}
\end{gathered}
$$

The equations above describe the optimization problem. In these formulations, $Q_{\text {load }}$ and Capacity $_{\text {rated }}$ are external variables which will be used as free input parameters. $m_{\text {air }}, T_{c h w, s e t}$ and $m_{c w}$ are parameters that need to be designed, here we let them be set points of the system during optimization. Other parameters can be collected from experimental data and catalog data. Consequently, the optimization problem can be rewritten as Eq. (5).

$$
\underset{T_{\text {chw }, \text { set }}, m_{\text {air }}, m_{c w}}{\text { Minize }} E_{\text {total }}\left(Q_{\text {load }}, m_{\text {air }}, T_{\text {chw }, \text { set }}, m_{c w}, \text { Capacity }_{\text {rated }}\right) \text { (5) }
$$

The above described optimization problem has many discrete variables and non-linear equations in different variables. To solve this problem, an AGA (adaptive genetic algorithms) method [14] is adopted.

\subsection{Optimization Algorithm}

In GA, the probabilities of crossover $P_{c}$ and mutation $P_{m}$ greatly determine the degree of solution accuracy and the convergence speed that genetic algorithms can obtain. Instead of using fixed values of $P_{c}$ and $P_{m}$, AGA utilize the population information in each generation and adaptively adjust $P_{c}$ and $P_{m}$ based on the fitness values of the solutions and defined coefficients $k_{1} \sim k_{4}$ in order to maintain the population diversity as well as to sustain the convergence capacity [14]. In this study, the fitness function is the total energy consumption of the system. The variables $T_{c h w, s e t}, m_{\text {air }}, m_{c w}$ are encoded into binary strings which form a chromosome. The ranges of parameters are limited by pre-defined constraint conditions.

\section{Case Study}

To show how the above optimization model can be applied, we simulate a GSHP system with one room, one GSHP chiller, one cold water pump and one cooling water pump.

\subsection{Calculation Conditions}

The AGA was run with the parameters summarized in Table 2. The cooling load is shown in Fig. 4. It is the cooling load of a $100 \mathrm{~m}^{2}$ classroom in our experimental building on a typical August day. The maximum cooling load is $8.6 \mathrm{~kW}$ and the cooling time is $9 \mathrm{~h}$. The rated capacity of the chiller is $11 \mathrm{~kW}$.
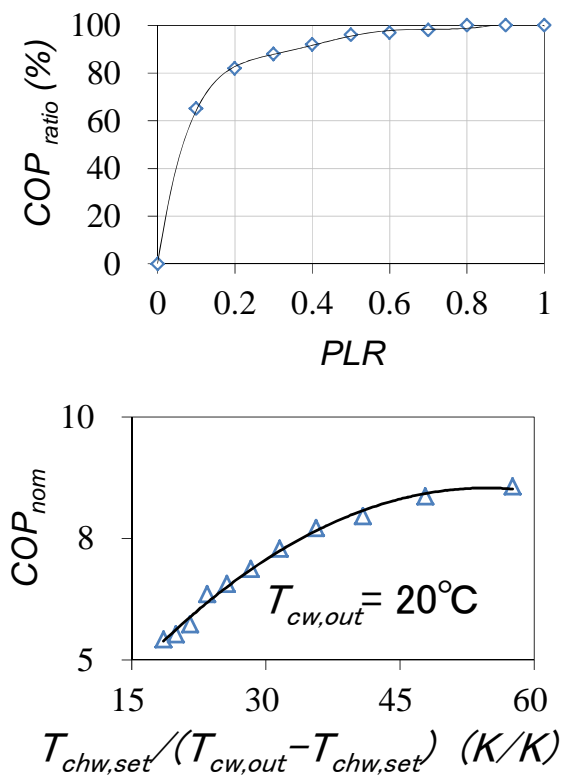

Fig. 2 COP values. 


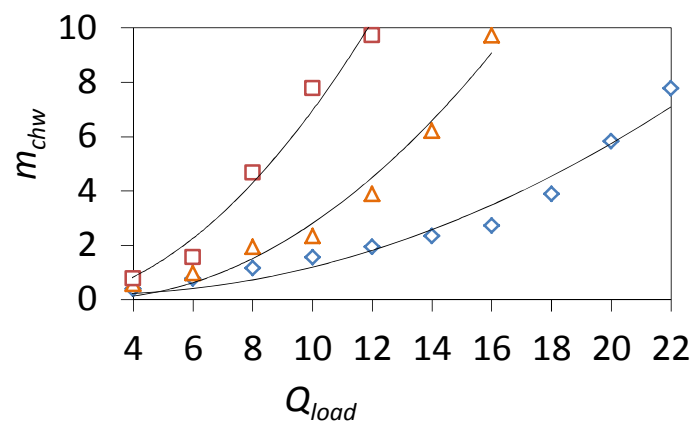

$\diamond$ Tchw, out: $5-7^{\circ} \mathrm{C}$

$\triangle$ Tchw, out: $10^{\circ} \mathrm{C}$

Tchw, out: $15^{\circ} \mathrm{C}$

Fig. 3 Cold water flow rate and cooling load.

\subsection{Optimal Design}

First, using the maximum cooling load and the rated capacity of $11 \mathrm{~kW}$ as conditions our AGA found the optimal set points with the minimum energy consumption of $1.9 \mathrm{~kW}$ (Table 3). We see, the system is optimal designed with $T_{\text {chw,set }}=13{ }^{\circ} \mathrm{C}, m_{\text {air }}=$ $3,700 \mathrm{~m}^{3} / \mathrm{h}$ and $m_{c w}=41 \mathrm{~L} / \mathrm{min}$.

Then, summation of system energy usage over one day are compared using an optimal case, case 1 and case 2 (Table 4 ). In case 1 , all the set points, $T_{c h w, s e t}$, $m_{\text {air }}$ and $m_{c w}$ are fixed to the optimization results in Table 3 to check the performance of this optimal designed system. Then in case 2 , the $T_{\text {chw,set was }}$ changed from $13{ }^{\circ} \mathrm{C}$ to $7^{\circ} \mathrm{C}$ and other parameters were set as the same value in Table 3 to check the sensitivity of the system total energy usage to $T_{c h w, s e t}$. To check the performance difference between this optimally designed system and a system operated with dynamic optimal set points, we calculated an optimal case. In this case, all the set points were found by optimization calculations for each given hourly cooling load value (Fig. 4); again, the energy consumption of the system was used as the objective function.

The results in Fig. 5 show that the energy consumption in Case 1 is almost the same as in the optimal case. Meanwhile, the optimally designed system with $T_{\text {chw,set }}=7{ }^{\circ} \mathrm{C}$ in case 2 results in the energy usage increasing by $10 \%$. The dynamic optimization set points for the optimal case is shown in Fig. 6. In the optimal case, except at 8:00 and 17:00 the $T_{\text {chw,set }}$ is $12.5^{\circ} \mathrm{C}$ or $13^{\circ} \mathrm{C}$ which is very close to or equal to the set temperature used in case 1 . Furthermore, the chiller uses about $80 \%$ energy of the system total energy consumption in all 3 cases (Fig. 7). As a result, the total energy consumption in case 1 and optimal case is almost same. In case 2, although the pumps and the fan use less energy than in the other two cases, the chiller uses about 22\% more electricity. We can see the trade-off relationship between chiller energy consumption and pump energy consumption. This results in the total energy consumption increase in case 2.

\section{$3.3 E_{\text {total }}$ vs $T_{\text {chw, set }}$ and PLR}

Fixing $m_{\text {air }}$ and $m_{c w}$ at the optimal values in Table 3, we calculated a day total energy consumption of the system with different temperature in a range of $7 \sim 15{ }^{\circ} \mathrm{C}$. To compare the energy consumption with different Capacity rated and PLR we calculated a unit capacity case, case 3 and case 4 (Table 5). In the unit capacity case, the Capacity $_{\text {rated }}$ was $11 \mathrm{~kW}$ and in case 3 and case 4 it was 1.2 times and 1.4 times larger, respectively.

The results in Fig. 8 show that $E_{\text {total }}$ for the day is decreasing when $T_{\text {chw, set }}$ is increasing from $7^{\circ} \mathrm{C}$ to $13{ }^{\circ} \mathrm{C}$, then increasing slightly as the temperature changes from $13^{\circ} \mathrm{C}$ to $15^{\circ} \mathrm{C}$. The energy consumption was higher in case 3 and case 4 compared to the unit capacity case. This is because the PLR in case 3 and case 4 are lower than for the unit capacity case as shown in Fig. 9. PLR was about 50\%-60\% in the unit capacity case and 30\%-50\% in case 3 and case 4 . 
Table 2 AGAs parameters.

\begin{tabular}{llll}
\hline \multirow{2}{*}{ Population size } & \multicolumn{3}{c}{ Probabilities of crossover and mutation } \\
\cline { 2 - 4 } & $k_{1}, k_{2}$ & $k_{3}, k_{4}$ & Maximum generation \\
\hline 200 & 0.01 & 0.04 & 1,200 \\
\hline
\end{tabular}

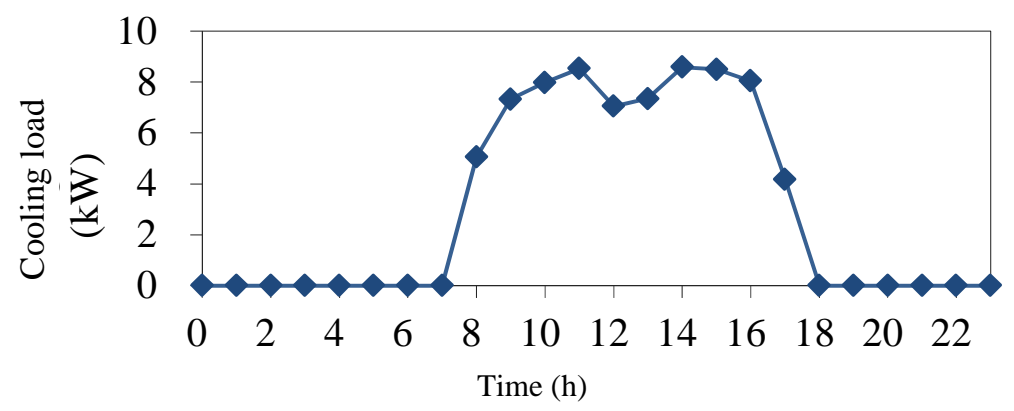

Fig. 4 Cooling load.

Table 3 Optimal design.

\begin{tabular}{llllll}
\hline \multirow{2}{*}{ Calculation conditions } & \multicolumn{4}{c}{ Optimization results } \\
\cline { 3 - 5 } & Optimal set points & $m_{c w}$ & Minimum \\
\hline$Q_{\text {load }}$ & Capacity & $E_{\text {rated }}$ & $T_{\text {chw, set }}$ & $m_{\text {air }}$ & \\
$8.6 \mathrm{~kW}$ & $11 \mathrm{~kW}$ & $13^{\circ} \mathrm{C}$ & $3,700 \mathrm{~m}^{3} / \mathrm{h}$ & $41 \mathrm{~L} / \mathrm{min}$ & $1.9 \mathrm{~kW}$ \\
\hline
\end{tabular}

Table 4 Calculation cases.

\begin{tabular}{llll}
\hline & Case 1 & Case 2 & Optimal case \\
\hline$T_{c h w, \text { set }}$ & Table 3 & Fixed at $7{ }^{\circ} \mathrm{C}$ & Dynamic optimization \\
$m_{\text {air }}, m_{c w}$ & Table 3 & Table 3 & Dynamic optimization \\
\hline
\end{tabular}

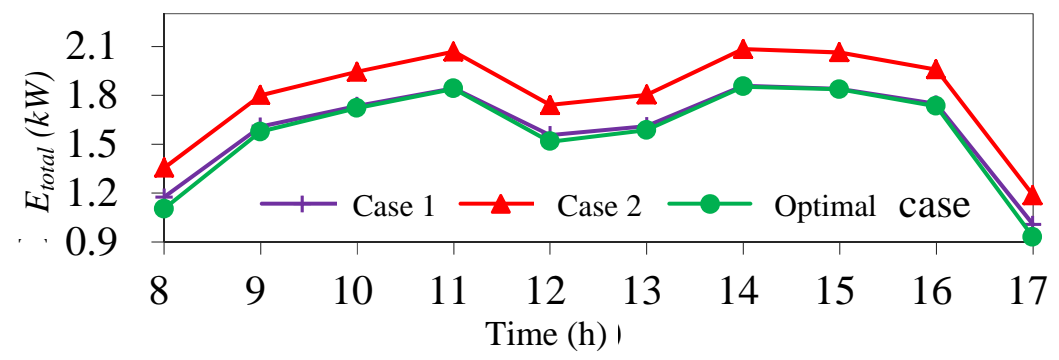

Fig. 5 Energy consumption over one day of operation for case 1, case 2 and optimal case.

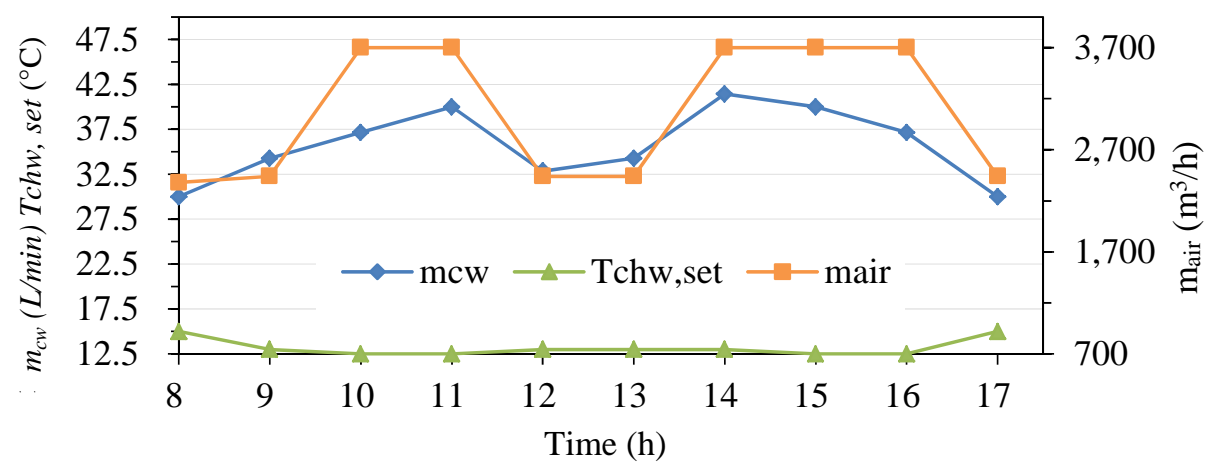

Fig. 6 Optimal set points of optimal case. 


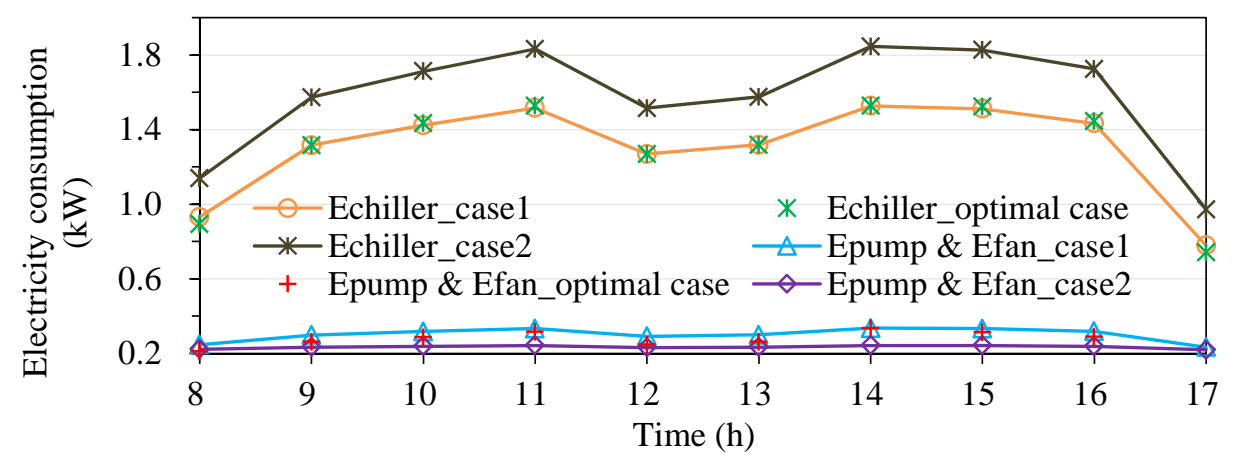

Fig. 7 Chiller electricity consumption vs. pumps \& fan electricity consumption.

Table 5 Calculation cases.

\begin{tabular}{llll}
\hline & Unit capacity case & Case 3 & Case 4 \\
\hline Capacity $_{\text {rated }}$ & $11 \mathrm{~kW}$ & $13.2 \mathrm{~kW}$ & $15.4 \mathrm{~kW}$ \\
$m_{\text {air }}, m_{c w}$ & Table 3 & & \\
\hline
\end{tabular}

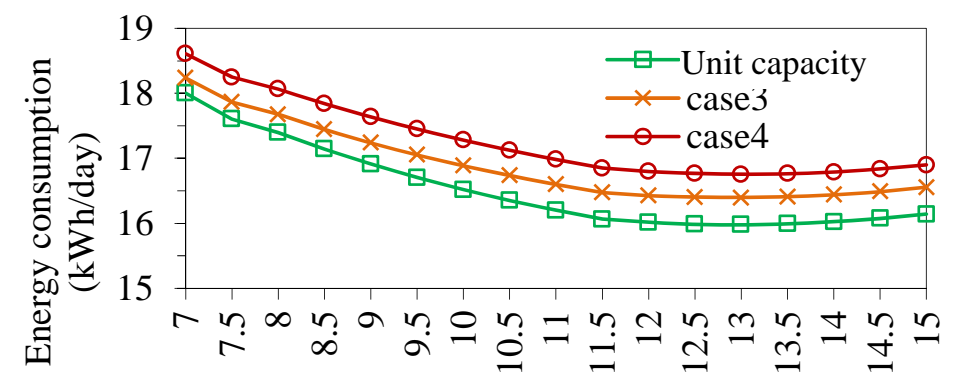

Tchw, set $\left({ }^{\circ} \mathrm{C}\right)$

Fig. 8 Energy consumption as a function of cold water temperature and heat pump capacity.

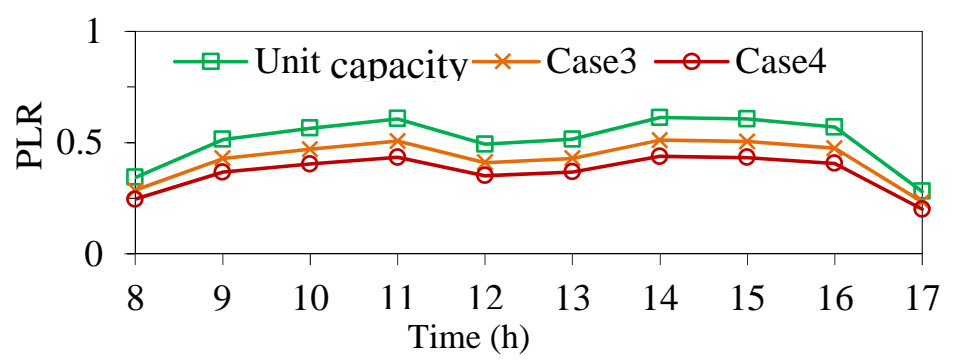

Fig. 9 PLR over the course of a day for different capacity cases.

\section{Conclusions}

In this study, a system consisting of BHE (borehole heat exchangers), a water-to-water heat pump and a FCU (fan coil unit) was modeled and simulated using MATLAB. A multi-variable evolutionary computation algorithm was proposed for generating optimal parameters for the system. As a result, an optimal system was designed with parameters that were calculated by minimizing system energy consumption.
Energy consumption of the system was about $10 \%$ lower than the system operated with a fixed supply cold water temperature $\left(7^{\circ} \mathrm{C}\right)$. Further result showed that the energy consumption increase due to decreasing PLR when the capacity is increased.

\section{References}

[1] Japan Meteorological Agency Home Page, http://www.jma.go.jp/jma/en/Activities/observations.html (accessed July 27, 2012). 
[2] J.W. Lund, D.H. Freeston, T.L. Boyd, Direct utilization of geothermal energy 2010 worldwide review, in: Proceedings World Geothermal Congress 2010, Bali, Indonesia, 2010.

[3] Y. Nam, R. Ooka, Heating and cooling experiments and feasibility study using heating and cooling load model for ground water heat pump system, J. Environ. Eng., AIJ 74 (638) 473-479.

[4] H. Arif, A. Ozay, H. Ebru, Experimental study of a closed loop vertical ground source heat pump system, Energy Conversion \& Management 44 (2003) 527-548.

[5] G.C. Luisa, K.N. Leslie, A design optimization tool based on a genetic algorithm, Automation in Construction 11 (2002) 173-184.

[6] M. Laurent, H. Fariborz, Multiobjective optimization of building design using TRNSYS simulations, genetic algorithm, and artificial neural network, Building and Environment 45 (2010) 739-746.

[7] L. Lu, W. Cai, L. Xie, S. Li, Y.C. Soh, HVAC system optimization-In-building section, Energy and Building 37 (2005) 11-22.

[8] K. Andrew, T. Fan, X. Guanglin, Multi-objective optimization of HVAC system with an evolutionary computation algorithm, Energy 36 (2011) 2440-2449.
[9] S. Hoseyn, H.A. Emad, A. Majid, Multi-objective optimization of a vertical ground source heat pump using evolutionary algorithm, Energy Conversion and Management 50 (2009) 2035-2046.

[10] T. Yashiro, R. Ooka, Zero energy building project in the University of Tokyo, in: 2011 Helsinki World Sustainable Building Conference, Finland, 2011.

[11] R. Li, R. Ooka, Optimiztion of ground source air-conditioning system configuration and operation, in: The 1st Asia Conference of International Building Performance Simulation Association, Shanghai, China, 2012.

[12] TESS Component Library Manual Home Page, http://www.tess-inc.com/trnsys.

[13] H. Yamaguchi, M. Miyata, H. Oda, M. Shioya, T. Watanabe, H. Niwa, et al., Experimental study of a cooling coil and the validation of its simulation model for the purpose of commissioning, Transactions of the Society of Heating, Air-Conditioning and Sanitary Engineers of Japan 143 (2009) 61-70.

[14] M. Srinivas, L.M. Patnaik, Adaptive probabilities of crossover and mutation in genetic algorithms, IEEE Transactions on Systems, Man and Cybernetics 24 (4) (1994) 656-667. 